\title{
Quantifying the effect of vegetation dynamics on the climate of the Last Glacial Maximum
}

\author{
A. Jahn ${ }^{1,2}$, M. Claussen ${ }^{1,3}$, A. Ganopolski ${ }^{1}$, and V. Brovkin ${ }^{1}$ \\ ${ }^{1}$ Potsdam Institute for Climate Impact Research (PIK), P.O. Box 601203, 14412 Potsdam, Germany \\ ${ }^{2}$ Now at Department of Atmospheric and Oceanic Sciences, McGill University, Burnside Hall Room 945, 805 Sherbrooke \\ Street West, Montreal, Quebec, H3A 2K6, Canada \\ ${ }^{3}$ Institute of Physics, Potsdam University, P.O. Box 601543, 14415 Potsdam, Germany
}

Received: 13 June 2005 - Published in Climate of the Past Discussions: 23 June 2005

Revised: 19 September 2005 - Accepted: 22 September 2005 - Published: 4 October 2005

\begin{abstract}
The importance of the biogeophysical atmosphere-vegetation feedback in comparison with the radiative effect of lower atmospheric $\mathrm{CO}_{2}$ concentrations and the presence of ice sheets at the last glacial maximum (LGM) is investigated with the climate system model CLIMBER-2. Equilibrium experiments reveal that most of the global cooling at the $\mathrm{LGM}\left(-5.1^{\circ} \mathrm{C}\right)$ relative to (natural) present-day conditions is caused by the introduction of ice sheets into the model $\left(-3.0^{\circ} \mathrm{C}\right)$, followed by the effect of lower atmospheric $\mathrm{CO}_{2}$ levels at the $\operatorname{LGM}\left(-1.5^{\circ} \mathrm{C}\right)$, while a synergy between these two factors appears to be very small on global average. The biogeophysical effects of changes in vegetation cover are found to cool the global LGM climate by $0.6^{\circ} \mathrm{C}$. The latter are most pronounced in the northern high latitudes, where the taiga-tundra feedback causes annually averaged temperature changes of up to $-2.0^{\circ} \mathrm{C}$, while the radiative effect of lower atmospheric $\mathrm{CO}_{2}$ in this region only produces a cooling of $1.5^{\circ} \mathrm{C}$. Hence, in this region, the temperature changes caused by vegetation dynamics at the LGM exceed the cooling due to lower atmospheric $\mathrm{CO}_{2}$ concentrations.
\end{abstract}

\section{Introduction}

The climate at the Last Glacial Maximum (LGM) around 21 kyr BP has already been modeled extensively in the past (e.g. PMIP, 2000). In most of these studies, the vegetation distribution was prescribed, either to proxy-based reconstructions or to the present-day potential vegetation distribution. In contrast to the potential present-day vegetation cover, vegetation reconstructions for the LGM show that forests were absent north of $55^{\circ} \mathrm{N}$, allowing herbaceous veg-

Correspondence to: A. Jahn

(alexandra.jahn@mail.mcgill.ca) etation to dominate these areas (Bigelow et al., 2003). Tropical forests in Asia, Africa, and Australia were also decreased; however, it is still debated whether the tropical forest in South America was also depleted during the LGM (Harrison and Prentice, 2003). In recent years, it has been shown that these differences in vegetation cover between presentday and the LGM played an important role in the climate system during the LGM. Crowley and Baum (1997) showed that a reconstructed vegetation distribution instead of a presentday vegetation cover led to changes large enough to reconcile model results with proxy data in some places. Levis et al. (1999) showed that the regional vegetation effect on climate is comparable to the radiative effect of a lowered $\mathrm{CO}_{2}$ level during the LGM. Kubatzki and Claussen (1998) explored the role of an interactive vegetation versus a prescribed presentday potential vegetation distribution during the LGM with a coupled atmosphere-vegetation model and showed that the interactive vegetation led to additional cooling over northern high latitudes. Wyputta and McAvaney (2001) compared the climatic effect of a prescribed present-day vegetation cover to that of a vegetation reconstruction for the LGM. They found that the use of the LGM reconstruction led to a widespread cooling in the northern high latitudes as well as in Australia and northern Africa, and to a warming over Alaska. The impact of the physiological effect of atmospheric $\mathrm{CO}_{2}$ concentrations on vegetation during the LGM was investigated by Harrison and Prentice (2003). They could show that forest cover was overestimated in LGM simulations when this effect was not included, especially in the tropics. However, oceanic feedbacks were missing in all of the above studies. Recently, Ganopolski (2003) performed a full atmosphere-ocean-vegetation (AOV) simulation for the LGM, showing that changes in ice sheets, atmospheric $\mathrm{CO}_{2}$ concentration, and vegetation cover, as well as the reorganization of the thermohaline circulation are important factors in understanding the glacial climate. Ganopolski (2003)

(C) 2005 Author(s). This work is licensed under a Creative Commons License. 
Table 1. Setup for all simulations. "PD" stands for present-day ice sheet forcing, "LGM" for LGM ice sheet forcing according to Peltier (1994). "280" and "190" stand for pre-industrial (i.e. "natural" present-day) and LGM atmospheric $\mathrm{CO}_{2}$ levels, respectively. "REF" stands for the use of a prescribed potential present-day vegetation distribution as simulated in $R E F$ while "interactive" stands for the use of the interactive vegetation model. The last column shows the simulated globally averaged annual mean surface air temperature of each simulation (in ${ }^{\circ} \mathrm{C}$ ).

\begin{tabular}{lcccc}
\hline Simulation & Ice sheets & $\mathrm{CO}_{2}$ & Vegetation & Global Temp. \\
\hline$R E F$ & PD & 280 & interactive & 13.99 \\
$L G M_{I}$ & LGM & 280 & REF & 11.03 \\
$L G M_{C}$ & PD & 190 & REF & 12.53 \\
$L G M_{C I}$ & LGM & 190 & REF & 9.48 \\
$L G M_{I V}$ & LGM & 280 & interactive & 10.55 \\
$L G M_{C V}$ & PD & 190 & interactive & 12.41 \\
$L G M_{C I V}$ & LGM & 190 & interactive & 8.86 \\
\hline
\end{tabular}

included only the biogeophysical vegetation feedback while Brovkin et al. (2002b) analyzed the effect of an interactive vegetation on the carbon cycle during the LGM with the same model.

Since the LGM climate has been simulated before with CLIMBER-2 (Ganopolski et al., 1998; Ganopolski, 2003), the goal of this study is to investigate the role of dynamic vegetation in comparison with the roles played by prescribed changes in ice-sheet cover and the radiative effect of a lower atmospheric $\mathrm{CO}_{2}$ concentration in the simulation of the LGM in a consistent way. We analyze the influence of these prescribed changes in comparison with the biogeophysical vegetation feedback to determine their individual contribution to the cooling at the LGM; however, we do not account for biogeochemical effects. In difference to Ganopolski (2003), we use factor separation and feedback analysis instead of factor analysis to investigate the climatic change caused by the different contributions. Due to this difference in technique, we can separate the pure contributions of $\mathrm{CO}_{2}$ change, ice sheet change and vegetation changes from synergistic effects between them. Furthermore, we are able to investigate the individual response of vegetation to lowered $\mathrm{CO}_{2}$ and imposed ice sheets with feedback analysis. Hence, this study is complementary to the work of Ganopolski (2003).

After comparing the individual effects of ice sheet and $\mathrm{CO}_{2}$ changes on the global annual surface air temperature with vegetation feedbacks, the ice sheet and $\mathrm{CO}_{2}$ factors are then compared with the results of Berger et al. (1996), who performed experiments with a 1-D radiative convective climate model in order to separate astronomical-albedo effects from the effect of $\mathrm{CO}_{2}$ changes. The comparison of vegetation feedbacks with ocean feedbacks will be the subject of a complementary study.

\section{Methods}

\subsection{Model}

CLIMBER-2 is a coarse resolution climate system model of intermediate complexity. It has a resolution of $10^{\circ}$ in latitude and $51^{\circ}$ in longitude. The atmospheric module is a 2.5 dimensional statistical-dynamical model and the ocean module is a multi-basin, zonally averaged ocean model with 20 uneven vertical levels that also includes a sea-ice model. The terrestrial vegetation model VECODE within CLIMBER-2 is a reduced-form dynamic global vegetation model (see Cramer et al., 2001), which simulates the dynamics of two plant functional types (PFTs), trees and grass, in response to changes in climate. The PFT fractions are parameterized as a continuous function of growing degree days (sum of mean daily temperature for days with a temperature above a certain threshold, here $0^{\circ} \mathrm{C}$ ) and annual precipitation. A more detailed description of CLIMBER-2 and its performance can be found in Petoukhov et al. (2000), Ganopolski et al. (2001), and Brovkin et al. (2002a).

\subsection{Experiments and LGM boundary conditions}

Several equilibrium experiments were performed for this study, using either present-day or LGM configurations for ice sheet cover and atmospheric $\mathrm{CO}_{2}$ concentration as well as interactive or fixed vegetation (see Table 1 for the setup of all simulations and Sect. 2.3 for a detailed explanation of these experiment). All experiments were integrated for 5000 years and the model output averaged over the last 10 years of the equilibrium state was analyzed in this paper.

For the LGM, continental ice sheets and a sea level drop of $105 \mathrm{~m}$ were prescribed for the simulations $L G M_{I}, L G M_{C I}$, $L G M_{I V}$, and $L G M_{C I V}$, based on reconstructions by Peltier (1994). Sea level and land-ocean distribution as well as a parametrization of gyres in the North Atlantic (due to the closure of the Canadian Archipelago during the LGM; see Ganopolski and Rahmstorf (2001) for details on this parametrization) are altered consistently with changes in ice sheet cover, although only the changes in ice sheets are mentioned explicitly in this paper. The $\mathrm{CO}_{2}$ was lowered from its pre-industrial value of $280 \mathrm{ppm}$ (assumed as "natural" present-day concentration) to $190 \mathrm{ppm}$ for all runs using LGM CO $\mathrm{CO}_{2}$ concentrations (Petit et al., 1999). For the vegetation, either the modeled potential present-day vegetation distribution from simulation $R E F$ was used or the vegetation model was used interactively, allowing it to adjust to the climatic effect of the respective changes in $\mathrm{CO}_{2}$ or ice sheets. Sensitivity studies revealed that using LGM orbital parameters instead of present-day values did not cause any significant changes, due to the very similar values of the orbital parameters at the LGM and at present. Therefore, we used present-day orbital parameters in all simulations for consistency. 


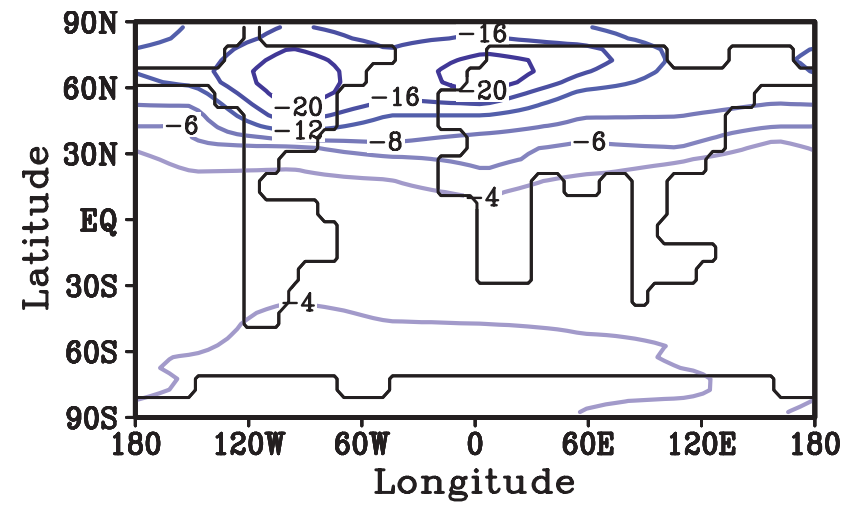

Fig. 1. Annually averaged surface air temperature differences (in $\left.{ }^{\circ} \mathrm{C}\right)$ between the full LGM simulation $\left(L G M_{C I V}\right)$ and the presentday reference run $R E F$.

\subsection{Factor separation and feedback analysis}

To quantify the individual contributions of the prescribed changes in $\mathrm{CO}_{2}$ concentration and ice sheet cover, a factor separation was performed following Stein and Alpert (1993). They developed this technique to separate pure contributions of different processes in a climate change signal from synergistic effects that result from non-linear processes in the climate system (Berger, 2001). In order to separate the pure contribution of $n$ factors from the synergies between them, $2^{n}$ simulations are necessary. Therefore four simulations were necessary: a present-day reference run $(R E F)$; a simulation with LGM ice sheets but reference $\mathrm{CO}_{2}$ concentration $\left(L G M_{I}\right)$; a simulation with $\mathrm{LGM} \mathrm{CO}_{2}$ concentration but reference ice cover $\left(L G M_{C}\right)$; and a run with both LGM ice sheets and LGM $\mathrm{CO}_{2}$ concentration $\left(L G M_{C I}\right)$. From the surface air temperatures at the end of these simulations ( $T_{0}, T_{I}, T_{C}, T_{C I}$, respectively), the two factors and the synergy term (caused by simultaneous changes in $\mathrm{CO}_{2}$ concentration and ice sheet cover) were calculated following Stein and Alpert (1993), i.e. $f_{I}=T_{I}-T_{0}, f_{C}=T_{C}-T_{0}$, and $f_{C I}=T_{C I}-\left(T_{C}-T_{0}\right)-\left(T_{I}-T_{0}\right)-T_{0}$.

To compare the temperature changes due to the changes in $\mathrm{CO}_{2}$ concentration and ice sheet cover with the temperature change caused by the vegetation feedbacks in response to the cooling caused by $\mathrm{CO}_{2}$ and ice sheet changes, a feedback analysis was performed. For this feedback analysis, three more experiments were necessary: a simulation with $\mathrm{LGM} \mathrm{CO}_{2}$ concentration and interactive vegetation $\left(L G M_{C V}\right)$; a run with $L G M$ ice sheets and interactive vegetation $\left(L G M_{I V}\right)$; and a simulation with LGM ice sheets, LGM $\mathrm{CO}_{2}$, and interactive vegetation $\left(L G M_{C I V}\right)$. These simulations provided the surface air temperatures $T_{C V}, T_{I V}$, and $T_{C I V}$, respectively. The feedback factors $f_{I}^{V}, f_{C}^{V}$, and $f_{C I}^{V}$ were then calculated as follows: $f_{C}^{V}=T_{C V}-T_{C}, f_{I}^{V}=T_{I V}-T_{I}$, and $f_{C I}^{V}=T_{C I V}-T_{C I}-\left(T_{C V}-T_{C}\right)-\left(T_{I V}-T_{I}\right)$.
Table 2. Annual averaged global temperature changes caused by the ice sheet factor $\left(f_{I}\right)$, the $\mathrm{CO}_{2}$ factor $\left(f_{C}\right)$, their synergy term $\left(f_{C I}\right)$, the vegetation feedback to the climatic change caused by the ice sheet factor $\left(f_{I}^{V}\right)$, the vegetation feedback to the climatic change caused by the $\mathrm{CO}_{2}$ factor $\left(f_{C}^{V}\right)$, and the vegetation feedback to the climatic change caused by the synergy term $\left(f_{C I}^{V}\right)$. The calculation of these terms is described in Sect. 2.3.

\begin{tabular}{cccc}
\hline Factors & Change in ${ }^{\circ} \mathrm{C}$ & Feedbacks & Change in ${ }^{\circ} \mathrm{C}$ \\
\hline$f_{I}$ & -2.96 & $f_{I}^{V}$ & -0.48 \\
$f_{C}$ & -1.46 & $f_{C}^{V}$ & -0.12 \\
$f_{C I}$ & -0.09 & $f_{C I}^{V}$ & -0.02 \\
\hline
\end{tabular}

In the factor separation, the forcing is prescribed, while in the feedback analysis, the feedback is a factor of the state of the system and it changes in response to the forcing. Here we have chosen ice sheets and $\mathrm{CO}_{2}$ as forcing/factor, because ice sheets and $\mathrm{CO}_{2}$ are not simulated interactively in the present version of CLIMBER. In both factor separation and feedback analysis, the same terms, such as pure contribution and synergy, appear, but there are different assumptions behind them. In the factor separation, the term $f_{C}$ reflects the response of the system to $\mathrm{CO}_{2}$ forcing. In the feedback analysis, the term $f_{C}^{V}$ reflect the response of the system to the vegetation changes that occur as reaction to the $\mathrm{CO}_{2}$ forcing. The synergy term $f_{C I}$ depicts the additional response of the system to applying both forcings, $\mathrm{CO}_{2}$ and ice sheets, simultaneously. The synergy term $f_{C I}^{V}$ shows the additional climate response due to the vegetation feedback to simultaneously applied $\mathrm{CO}_{2}$ and ice sheets forcing.

\section{Results}

The LGM climate simulated in the full LGM experiment $\left(L G M_{C I V}\right)$ shows a global annual mean surface air temperature of $8.9^{\circ} \mathrm{C}$, which is $5.1^{\circ} \mathrm{C}$ lower than in the present-day reference run $(R E F)$. This temperature decrease is in the range of simulated changes from AOGCMs that find a LGM cooling between $3.8^{\circ} \mathrm{C}$ (Hewitt et al., 2003) and $10^{\circ} \mathrm{C}$ (Kim et al., 2003). The cooling is centered over the ice sheets of the northern hemisphere $(\mathrm{NH})$ and is much weaker over the southern hemisphere (SH) (Fig. 1).

This global LGM cooling of $5.1^{\circ} \mathrm{C}$ can be attributed to the ice sheet and $\mathrm{CO}_{2}$ factors, their synergy, and the vegetation feedback to each of these terms by factor separation and feedback analysis (see Table 2). The largest part of the global cooling is due to the presence of LGM ice sheets $\left(f_{I}\right)$, which leads to a global cooling of $3.0^{\circ} \mathrm{C}$, followed by the effect of the $\mathrm{CO}_{2}$ drop to $190 \mathrm{ppm}\left(f_{C}\right)$, which results in a global temperature decrease of $1.5^{\circ} \mathrm{C}$. The term $f_{I}^{V}$, describing the temperature change caused by the vegetation feedback to the 
(a)

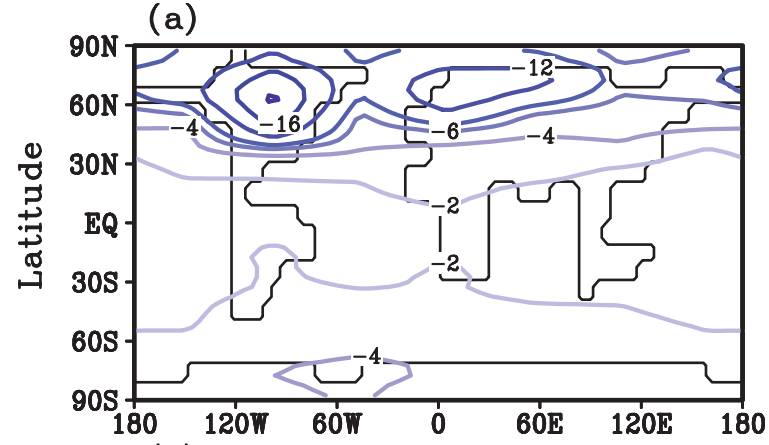

(c)

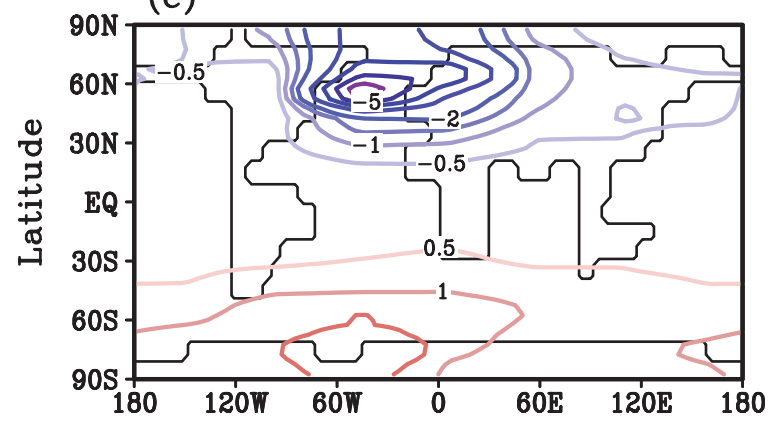

(e)

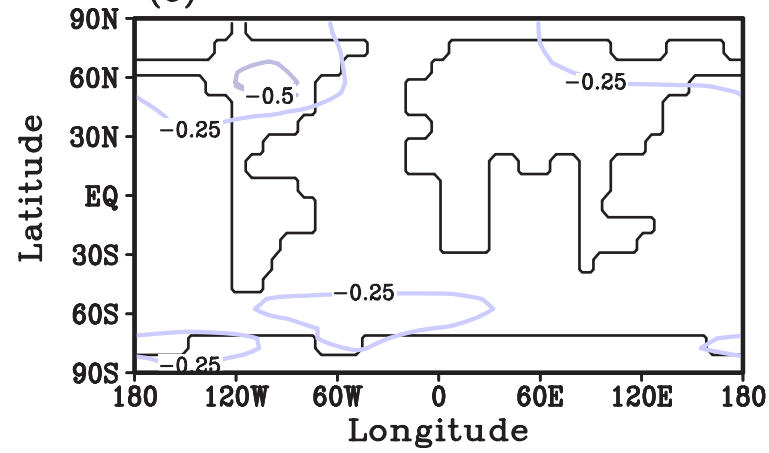

(b)

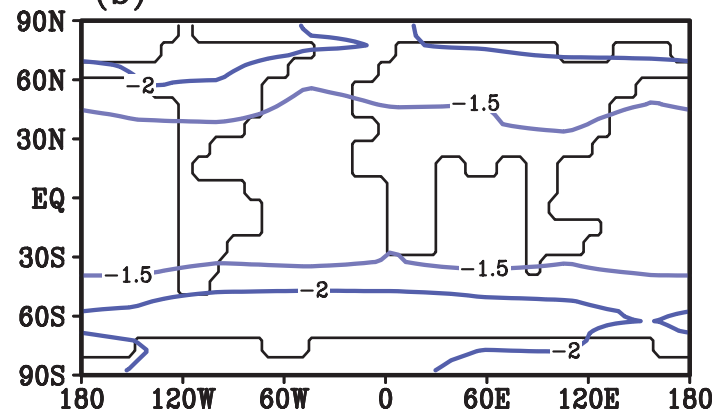

(d)

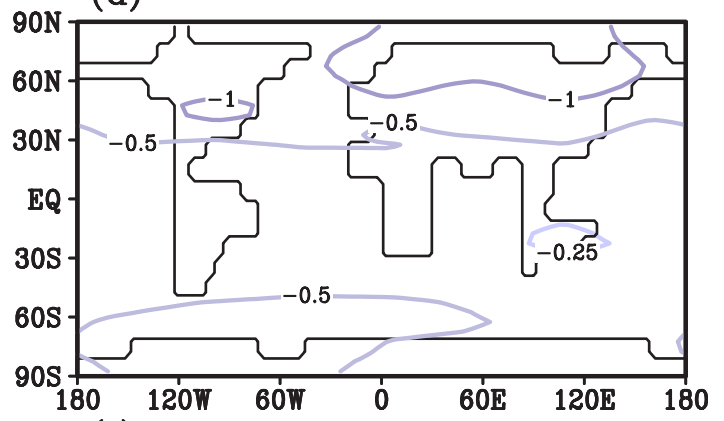

(f)

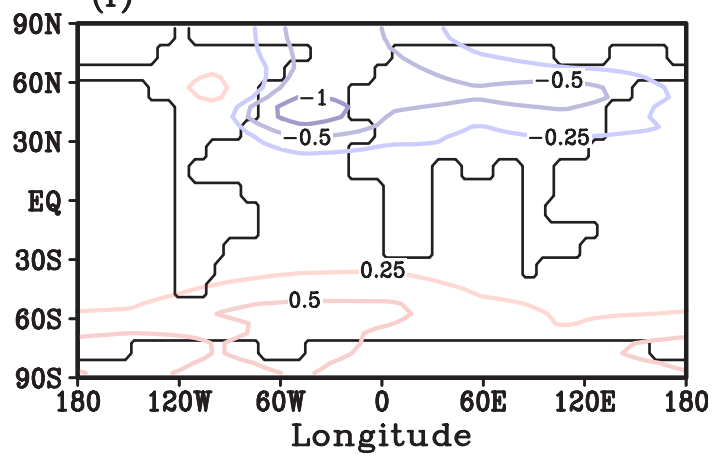

Fig. 2. Annually averaged surface air temperature changes (in ${ }^{\circ} \mathrm{C}$ ) caused by (a) the presence of an ice sheet $\left(f_{I}\right)$, (b) lowering of $\mathrm{CO}_{2}$ to $190 \mathrm{ppm}\left(f_{C}\right)$, (c) synergy between ice sheets and $\mathrm{CO}_{2}$ decrease $\left(f_{C I}\right),(\mathbf{d})$ vegetation change in response to an ice sheet $\left(f_{I}^{V}\right)$, (e) vegetation change in response to the lowered $\mathrm{CO}_{2}\left(f_{C}^{V}\right)$, and (f) vegetation change in response to the synergy between presence of ice sheets and $\mathrm{CO}_{2}$ lowering $\left(f_{C I}^{V}\right)$.

cooling produced by the LGM ice sheets, leads to an additional global temperature decrease of $0.5^{\circ} \mathrm{C}$. The vegetation feedback to the cooling caused by the lower $\mathrm{CO}_{2}\left(f_{C}^{V}\right)$ produces a cooling of $0.1^{\circ} \mathrm{C}$, which is the same amount of cooling as generated by $f_{C I}$ (the additional temperature change due to the simultaneous $\mathrm{CO}_{2}$ and ice sheet change). The vegetation feedback to the cooling caused by the synergy between $\mathrm{CO}_{2}$ and ice sheet forcing $\left(f_{C I}^{V}\right)$ leads to a global temperature decrease of substantially less than $0.1^{\circ} \mathrm{C}$.

As shown in Fig. 2, there is considerable variation in the regional distribution of the cooling due to each of these factors/feedback terms. The presence of ice sheets causes a cooling mainly over the ice covered regions of the NH due to the increase in albedo and altitude (Fig. 2a). The cooling in the NH leads to an increase in the Atlantic overturning circulation by $7 \mathrm{~Sv}$; this increases the northward heat transport by $0.2 \mathrm{PW}$, thereby cooling the Southern Ocean. As a consequence, sea-ice cover in the SH increases, which further decreases the temperature in southern high latitudes due to the sea-ice-albedo feedback. The $\mathrm{CO}_{2}$ factor $f_{C}$ generates the strongest cooling in the high latitudes of both hemispheres; however, the cooling is larger in the SH than in the NH (Fig. 2b). The stronger cooling in the high latitudes ("polar amplification") is caused by the positive sea-ice-albedo and snow-albedo feedbacks operating in both hemispheres. At the same time, the northward oceanic heat transport is strengthened at lower atmospheric $\mathrm{CO}_{2}$ concentrations; however, this change is smaller as that found for $f_{I}$. This strengthening of northward heat transport serves as a negative feedback in the $\mathrm{NH}$, and as additional positive feedback 
(a)

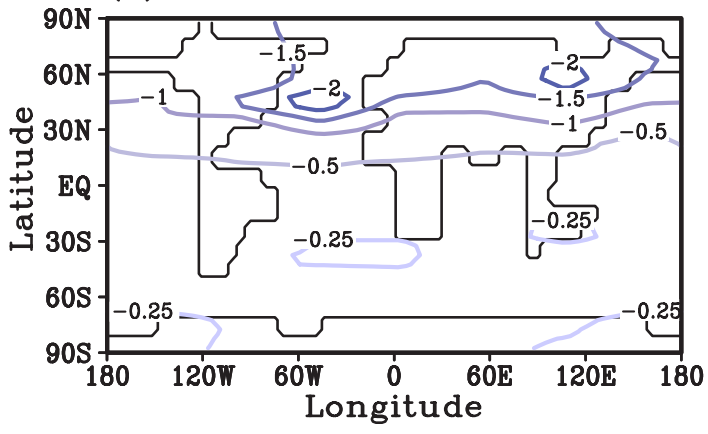

(b)

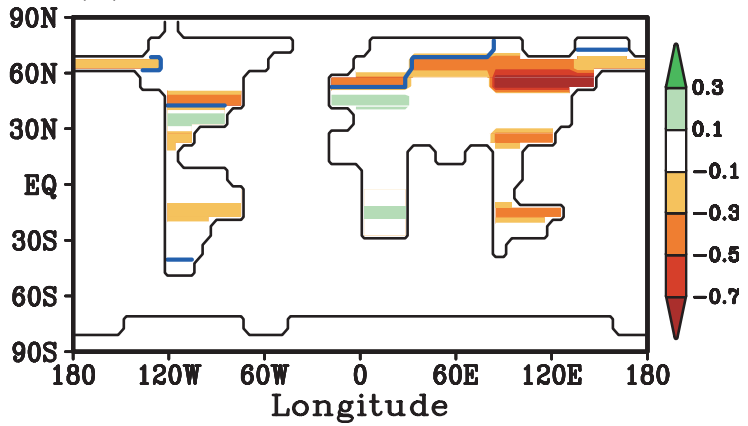

Fig. 3. (a) Change in the annually averaged surface air temperature due to the biogeophysical vegetation feedbacks (in ${ }^{\circ} \mathrm{C}$ ) and (b) the associated change in fractional tree coverage compared to the prescribed potential present-day vegetation cover (i.e. vegetation change between $L G M_{C I}$ and $L G M_{C I V}$ ). The blue line in (b) represents the boundary of $60 \%$ inland ice coverage within a grid cell.

in the SH, which explains the stronger cooling in the high latitudes of the SH compared to the NH. The synergy factor $f_{C I}$ produces a strong cooling over the North Atlantic and a warming over the Southern Ocean (Fig. 2c). This temperature change is caused by a decrease in northward heat transport in the ocean and a displacement of the deep water formation site to the south, which means that the ocean circulation changes from its "warm" mode (in which it is in $R E F, L G M_{I}$, and $L G M_{C}$ ) to its "cold" mode (in $L G M_{C I}$ ) (see Ganopolski and Rahmstorf, 2001, Fig. 2).

As shown in Ganopolski and Rahmstorf (2001), the bifurcation transition between cold and warm modes occurs in the domain of negative anomalous freshwater forcing for the full glacial conditions. However, for a somewhat warmer climate, the position of bifurcation transition moves to the domain of positive freshwater flux, i.e. the warm mode becomes stable under zero freshwater anomalous flux. Thereby the global cooling is another bifurcation parameter of the model, and for unperturbed freshwater flux, the global temperature determines which mode of the thermohaline circulation is stable. The critical temperature threshold is crossed in this study when $\mathrm{CO}_{2}$ and ice sheets are changed simultaneously to LGM conditions (i.e. in $L G M_{C I}$ ). As intended by Stein and Alpert (1993), the effect of this non-linear climate response is captured by the synergy term $f_{C I}$. However, sensitivity studies show that the combined cooling due to $\mathrm{CO}_{2}$ decrease and presence of ice sheets is just large enough to trigger the change in the ocean circulation. A slightly smaller cooling, as caused for example by a $\mathrm{CO}_{2}$ concentration of $200 \mathrm{ppm}$ instead of $190 \mathrm{ppm}$ in combination with ice sheets, does not cause this change in the ocean circulation mode. In this case, the additional cooling produced by the vegetation feedback triggers the change in the ocean circulation, and the large temperature change associated with it is then included in the term $f_{C I}^{V}$. This could lead to a misinterpretation of the term $f_{C I}^{V}$, since the large temperature change is not produced by vegetation feedbacks per se, but by a nonlinear process that is only triggered by the effect of vegetation feedbacks. Therefore, care has to be taken to not confuse the effect of non-linear processes with the effect of climate feedbacks when calculating individual contributions of feedbacks close to bifurcation points in the climate system.

The cooling effect of $f_{I}^{V}$ is strongest over land in the northern high latitudes (Fig. 2d). It is due to the replacement of forest by herbaceous vegetation in response to the cooling caused by the ice sheet factor $\left(f_{I}\right)$, which increases the albedo of these regions especially in winter and spring when the surface is snow covered (see Brovkin et al., 2003). In addition, this so called taiga-tundra feedback is amplified by an increase in snow coverage over these regions. The cooling generated by $f_{C}^{V}$ is strongest over North America (Fig. 2e), as a result of the taiga-tundra feedback in this region. As seen in Fig. 2f, $f_{C I}^{V}$ causes the strongest cooling over the North Atlantic and northern latitudes of Eurasia, combined with a warming of the Southern Ocean. The cooling over the North Atlantic is a result of a further decrease of the northward heat transport and an associated increase in sea-ice cover compared to $L G M_{C I}$. The decrease in northward heat transport is also responsible for the warming in the SH. In the northern latitudes of Eurasia, $f_{C I}^{V}$ shows a cooling over regions where tree cover decreases, again due to the taiga-tundra feedback.

To compare the cooling caused by the total vegetation feedback with the radiative effect of lowered atmospheric $\mathrm{CO}_{2}$ concentrations, the temperature changes of all three vegetation feedback terms are added (Fig. 3a). Over the land areas of northern Siberia, the combined effect of the vegetation changes leads to a cooling of about $2^{\circ} \mathrm{C}$, while the $\mathrm{CO}_{2}$ reduction to $190 \mathrm{ppm}$ in $f_{C}$ (Fig. 2b) causes a temperature decrease of $1.5^{\circ} \mathrm{C}$ in this region. This strong cooling by the vegetation occurs exactly in those regions with the greatest decrease in tree cover (as shown in Fig. 3b). Hence, even though the cooling effect of the $\mathrm{CO}_{2}$ factor makes up $29 \%$ of the global cooling, while the total vegetation feedback only causes $12 \%$ of the global temperature change, the cooling due to the vegetation feedback in the high latitudes of eastern Eurasia is larger than the $\mathrm{CO}_{2}$ induced cooling in this region. 
To evaluate the results of this study, the temperature changes caused by the factors $f_{I}$ and $f_{C}$ are compared with the factors calculated by Berger et al. (1996). They found that the increase in albedo due to the presence of an LGM ice sheet, combined with the changed orbital parameters, leads to a cooling of $3.0^{\circ} \mathrm{C}$ at the LGM, while the lowering of the $\mathrm{CO}_{2}$ level by $136 \mathrm{ppm}$ cooled the climate by $1.6^{\circ} \mathrm{C}$. In CLIMBER-2, the presence of an ice sheet causes a temperature change of $-3.0^{\circ} \mathrm{C}$, and even if we add the very small effect of changed orbital parameters and its synergy with ice sheets (as found in sensitivity studies), the cooling by the ice sheet and orbital parameter factor still is $3.0^{\circ} \mathrm{C}$. The lowering of the $\mathrm{CO}_{2}$ level by $90 \mathrm{ppm}$ to $190 \mathrm{ppm}$ produces a cooling of $1.5^{\circ} \mathrm{C}$ in CLIMBER-2. Together with the small positive synergy factor between these two factors, Berger et al. (1996) found a LGM cooling of $4.5^{\circ} \mathrm{C}$. This is the same cooling as found in the CLIMBER-2 simulation with fixed present-day vegetation (i.e. experiment $L G M_{C I}$ ). The larger $\mathrm{CO}_{2}$ decrease of $136 \mathrm{ppm}$ in Berger et al. (1996) caused a temperature change for the $\mathrm{CO}_{2}$ factor that is only slightly larger than the one found in CLIMBER-2 with a $\mathrm{CO}_{2}$ reduction of only $90 \mathrm{ppm}$. This is consistent with the smaller sensitivity of the model of Berger et al. (1996) to a doubling of $\mathrm{CO}_{2}\left(1.8^{\circ} \mathrm{C}\right)$, as compared with the $\mathrm{CO}_{2}$ sensitivity of CLIMBER-2 $\left(2.6^{\circ} \mathrm{C}\right)$. Therefore, it can be concluded that the individual effects of the factors $f_{I}$ and $f_{C}$ are consistent with the results of Berger et al. (1996).

\section{Conclusions}

Although globally the biogeophysical effect of vegetation dynamics on air temperature is less important for the LGM climate than the impact of $\mathrm{CO}_{2}$ changes and the presence of ice sheets, it was shown that in the northern high latitudes of Eurasia vegetation changes have a cooling effect that exceeds the temperature decrease due to the $\mathrm{CO}_{2}$ decrease in this region. Hence, the use of a dynamic vegetation module instead of a prescribed present-day vegetation distribution is important as it causes significant temperature changes on a regional scale. This is especially important for the LGM, since Brovkin et al. (2003) showed that climate-vegetation interactions in the northern high latitudes are stronger in colder climates than in warmer climates, due to a longer snow season in colder climates that increases the radiative effect of the taiga-tundra effect in northern latitudes.

Furthermore, the factor separation showed that in CLIMBER-2 the influence of the $\mathrm{CO}_{2}$ drop at the LGM is distributed over both hemispheres; however, it is stronger over the SH due to ocean effects. The cooling caused by the ice sheets is strongest over the ice covered regions of the $\mathrm{NH}$. A comparison of the globally averaged cooling caused by the presence of ice sheets and $\mathrm{CO}_{2}$ reduction at the LGM with the results of Berger et al. (1996) shows that these two factors are in good agreement in both studies.
Acknowledgement. The authors would like to thank C. Kubatzki for constructive discussions and M.-F. Loutre, S. Levis, L. A. Mysak and an anonymous referee for helpful comments that improved the manuscript. During the preparation of the actual manuscript, A. Jahn was supported by a Canadian NSERC Discovery Grant awarded to L. A. Mysak.

Edited by: G. M. Ganssen

\section{References}

Berger, A.: The role of $\mathrm{CO}_{2}$, sea-level and vegetation during the Milankovitch-forced glacial-interglacial cycles, in: GeosphereBiosphere Interactions and Climate, Proceedings of the workshop held at Pontifical Academy of Science, edited by: Bengtsson, L. O. and Hammer, C. U., Cambridge University Press, 119146, 2001.

Berger, A., Dutrieux, A., Loutre, M. F., and Tricot, C.: Paleoclimate sensitivity to $\mathrm{CO}_{2}$ and insolation, Scientific Report 1996/6, Institut d'Astronomie et Géophysique Georges Lemaître, Université Catholique de Louvain, Louvain-la-Neuve, 1996.

Bigelow, N. H., Brubaker, L. B., Edwards, M. E., Harrison, S. P., Prentice, I. C., Anderson, P. M., Andreev, A. A., Bartlein, P. J., Christensen, T. R., Cramer, W., Kaplan, J. O., Lozhkin, A. V., Matveyeva, N. V., Murray, D. F., McGuire, A. D., Gajewski, K., Wolf, V., Holmqvist, B. H., Igarashi, Y., Kremenetskii, K., Paus, A., Pisaric, M. F. J., and Volkova, V. S.: Climate change and Arctic ecosystems: 1 . Vegetation changes north of $55^{\circ} \mathrm{N}$ between the last glacial maximum, mid-Holocene, and present, J. Geophys. Res., 108, doi: 10.1029/2002JD002 558, 2003.

Brovkin, V., Claussen, M., Ganopolski, A., Bendtsen, J., Kubatzki, C., Petoukhov, V., and Andreev, A.: Carbon Cycle, vegetation and climate dynamics in the Holocene: Experiments with the CLIMBER-2 model, Global Geochemical Cycles, 16, doi:10.1029/2001GB001 662, 2002a.

Brovkin, V., Hoffmann, M., Bendtsen, J., and Ganopolski, A.: Ocean biology could control atmospheric $\delta^{13} \mathrm{C}$ during glacial-interglacial cycle, Geochem., Geophys., Geosyst., 3, doi:10.1029/2001GC000 270, 2002b.

Brovkin, V., Levis, S., Loutre, M.-F., Crucifix, M., Claussen, M., Ganopolski, A., and C. Kubatzki, V. P.: Stability analysis of the climate-vegetation system in the northern high latitudes, Clim. Change, 57, 119-138, 2003.

Cramer, W., Bondeau, A., Woodward, F. I., Prentice, I. C., Betts, R. A., Brovkin, V., Cox, P. M., Fisher, V., Foley, J., Friend, A. D., Kucharik, C., Lomas, M. R., Ramankutty, N., Sitch, S., Smith, B., White, A., and Young-Molling, C.: Dynamic responses of global terrestrial ecosystems to changes in $\mathrm{CO}_{2}$ and climate, Global Change Biol., 7, 357-373, 2001.

Crowley, T. J. and Baum, S.: Effect of vegetation on an ice-age climate model simulation, J. Geophys. Res., 102, 463-480, 1997.

Ganopolski, A.: Glacial integrative modelling, Phil. Trans. Royal. Soc. Lond., 361, 1871-1884, 2003.

Ganopolski, A. and Rahmstorf, S.: Rapid changes of glacial climate simulated in a coupled climate model, Nature, 409, 153158, 2001.

Ganopolski, A., Rahmstorf, S., Petoukhov, V., and Claussen, M.: Simulation of modern and glacial climates with a coupled global model of intermediate complexity, Nature, 391, 351-356, 1998. 
Ganopolski, A., Petoukhov, V., Rahmstorf, S., Brovkin, V., Claussen, M., Eliseev, A., and Kubatzki, C.: CLIMBER-2: a climate system model of intermediate complexity, Part II: model sensitivity, Clim. Dyn., 17, 735-751, 2001.

Harrison, S. P. and Prentice, C. I.: Climate and $\mathrm{CO}_{2}$ controls on global vegetation distribution at the last glacial maximum: analysis based on palaeovegetation data, biome modelling and palaeoclimate simulations, Global Change Biol., 9, 983-1004, 2003.

Hewitt, C. D., Stouffer, R. J., Broccoli, A. J., Mitchell, J. F. B., and Valdes, P. J.: The effect of ocean dynamics in a coupled GCM simulation of the Last Glacial Maximum, Clim. Dyn., 20, 203218, 2003.

Kim, S.-J., Flato, G. M., and Boer, G. J.: A coupled climate model simulation of the Last Glacial Maximum, Part 2: approach to equilibrium, Clim. Dyn., 20, 635-661, 2003.

Kubatzki, C. and Claussen, M.: Simulation of the global biogeophysical interactions during the Last Glacial Maximum, Clim. Dyn., 14, 461-471, 1998.

Levis, S., Foley, J. A., and Pollard, D.: $\mathrm{CO}_{2}$, climate, and vegetation feedbacks at the Last Glacial Maximum, J. Geophys. Res., 104, 191-198, 1999
Peltier, W. R.: Ice Age Paleotopography, Science, 256, 195-201, 1994.

Petit, J. R., Jouzel, J., Raynaud, D., Barkov, N. I., Barnola, J.-M., Basile, I., Bender, M., Chappellaz, J., Davis, M., Delaygue, G., Delmotte, M., Kotlyakov, V. M., Legrand, M., Lipenkov, V. Y., Lorius, C., Pepin, L., Ritz, C., Saltzman, E., and Stievenard, M.: Climate and atmospheric history of the past 420,000 years from the Vostok ice core, Antarctica, Nature, 399, 429-436, 1999.

Petoukhov, V., Ganopolski, A., Brovkin, V., Claussen, M., Eliseev, A., Kubatzki, C., and Rahmstorf, S.: CLIMBER-2: a climate system model of intermediate complexity, Part I: model description and performance for present climate, Clim. Dyn., 16, 1-17, 2000.

PMIP: Paleoclimate Modeling Intercomparison Project (PMIP), in: Proceedings of the third PMIP workshop, edited by Braconnot, P., vol. WCRP-111, WMO/TD-1007, p. 271, Canada, 2000.

Stein, U. and Alpert, P.: Factor Separation in numerical simulations, J. Atmos. Sci., 50, 2107-2115, 1993.

Wyputta, U. and McAvaney, B. J.: Influence of vegetation changes during the Last Glacial Maximum using the BMRC atmospheric general circulation model, Clim. Dyn., 17, 923-932, 2001. 